удК 69:005.8

Т. И. Кубасова

Байкальский государственный университет, 2. Иркутск, Российская Федеращия

\title{
ОРГАНИЗАЦИОННОЕ ПРОЕКТИРОВАНИЕ ЛОГИСТИЧЕСКИХ ИПОТЕЧНО-СТРОИТЕЛЬНЫХ СИСТЕМ КОАЛИЦИОННОГО ТИПА
}

\begin{abstract}
АНнотАЦИЯ. В современной экономике процессно-ориентированный подход управления бизнесом все чаще заменяется на проектно-ориентированный подход. Это вызвано, прежде всего, масштабными изменениями, высокими рисками принятия решений, которые, в свою очередь, требуют переосмысления классических и поиска новых, инновационных подходов к управлению развитием бизнеса в постоянно меняющейся среде. Проектный офис, как наивысшая форма управления проектной деятельностью, за последнее десятилетие эволюционировал с уровня крупных корпораций до государственного уровня управления. В данной статье рассматриваются теоретические вопросы организационного проектирования сложных управленческих систем, к которым относятся логистические ипотечно-строительные системы и даются научно-практические рекомендации по системной организации коалиционного управленческого органа для реализации федерального проекта «Ипотека и арендное жилье».

кЛючЕВЫЕ СЛОВА. Проектно-ориентированный подход; логистические системы; ипотечно-строительные системы; дивизиональная структура; коалиционная структура; проектный офис.

ИНФОРМАЦИЯ О СТАТЬЕ. Дата поступления 12 октября 2016 г.; дата принятия к печати 2 ноября 2016 г.; дата онлайн-размещения 30 ноября 2016 г.
\end{abstract}

T. I. Kubasova Baikal State University, Irkutsk, Russian Federation

\section{ORGANIZATIONAL DESIGNING OF LOGISTIC MORTGAGE AND CONSTRUCTION SYSTEMS OF COALITION TYPE}

\begin{abstract}
In present-day economy, the procedure-oriented approach to business management is more frequently replaced by the project-oriented approach. It results, first of all, from large-scale changes, high risk of decision-making, which, in their turn, demand to rethink the classical approaches and search for new innovative ones in business development management in the constantly changing environment. The project office, as the highest form of project activity management, has developed during the last decade from the large corporation level to the level of governmental management. The article considers theoretical issues of organizational designing of complex managerial systems, involving logistic mortgage and construction systems, and gives scientific and practical recommendation on system organization of the project office in implementing the federal project «Mortgage and Rental Housing» . KEYWORDS. Project-oriented approach; logistic systems; mortgage and construction systems; divisional structure; coalition structure; project office.

ARTICLE INFO. Received October 17, 2016; accepted November 2, 2016; available online November 30, 2016.
\end{abstract}

В настоящее время в современной экономике происходят масштабные изменения, которые требуют переосмысления классических и поиска новых, инновационных подходов к управлению развитием бизнеса. Увеличивающаяся скорость,

(C) В. М. Рыков, Л. М. Дулина, 2016

\section{Baikal Research Journal}

электронный научный журнал Байкальского государственного университета 
масштаб и качество изменений, происходящих в экономике, можно рассматривать как предпосылку интеграции теории логистики и теории управления проектами в свете развития адаптационной способности потенциала логистики к решению задач в рамках управления проектами. Эти изменения являются предметом изучения международных и отечественных специалистов различных отраслей науки [1-3]. В данной статье рассматриваются вопросы организационного проектирования сложных управленческих систем, к которым относятся логистические ипотечно-строительные системы, а также представлены научно-практические рекомендации по их внедрению на примере проекта Агентства по ипотечному жилищному кредитованию (АИЖК) - «Ипотека и арендное жилье».

Предпосылкой написания данной статьи явилось утверждение Положения о проектном офисе ${ }^{1}$, на основе которого предполагается реализация социально значимых проектов общенационального масштаба в рамках проектного подхода. В том числе среди девяти направлений коалиционного управленческого органа (проектного офиса), которые получат дополнительное государственное финансирование, проект АИжК «Ипотека и арендное жилье», на который выделено 10 млрд р. ${ }^{2}$

Таким образом, идеология проектного офиса выходит на государственный уровень, предполагая создание эффективной инфраструктуры для реализации проектов государственно значимых проектов и направлена «на решение трех главных задач управления проектами:

1. Обеспечение коммуникаций;

2. Взаимодействие с субподрядчиками;

3. Сокращение затрат» [2].

В соответствии с утвержденным Положением о проектном офисе, организация исполнения на рынке ипотечного кредитования и арендного жилья возложена на действующих лиц проекта. К функциональному заказчику (Министерство строительства и ЖКХ Российской Федерации), куратору (вице-премьер) и руководителю проекта (Министерство строительства и ЖКХ Российской Федерации, АО АИЖКК) добавились старшее должностное лицо проекта и администратор. Первый находится между куратором и руководителем проекта: оказывает содействие, дает консультации, его задача - повысить вес проекта. Администратор отвечает за организационно-техническое обеспечение. Участников проектного офиса дополняет перечень заинтересованных лиц (стейкхолдеров): крупные девелоперы, банки/ ипотечные агенты, АО АИЖК, Министерство финансов Российской Федерации, Министерство экономического развития Российской Федерации, Банк России.

Появление Координационного центра в системе управления ипотечно-строительными системами в виде проектного офиса, повлечет изменения в сложившейся организационной структуре АИЖК и его партнеров. Эффективность управления проектным офисом во многом зависит от эффективности принятой структуры управления проекта с учетом особенностей всех участников. В предыдущих работах [4-6] нами были раскрыты основные методологические принципы и подходы позиционирования ипотечно-строительных проектов в общей системе инвестиционно-строительных проектов, поэтому в данной статье мы будем использовать термины «ипотечно-строительный проект» и «логистическая ипотечно-строительная система», как основополагающие при организационном проектировании управленческих систем на рынке жилищного строительства и ипотечного кредитования.

${ }^{1}$ Правительство утвердило положение о проектном офисе // Ведомости. 2016. 14 окт.

2 Правительство утвердило девять направлений проектного офиса, которые получат дополнительное финансирование: здравоохранение - 220 млн р., образование $-14,2$ млрд р., ипотека и арендное жилье - 10 млрд р., ЖККХ и городская среда - 5 млрд р., международная кооперация и экспорт $-16,1$ млрд р., экология $-20,1$ млрд р. (Ведомости. 2016. 14 окт.)

\section{Baikal Research Journal}

электронный научный журнал Байкальского государственного университета 
При их теоретическом рассмотрении необходимо учесть основополагающие моменты, к которым относятся: сущность управления (системные свойства); системообразующие процессы (в форме законов и закономерностей); процессы структуризации системы.

Интегративное начало в управлении логистических ипотечно-строительных проектов может быть обеспечено переводом управления на системную основу с созданием одноименных проектно-ориентированных систем (далее - логистических ипотечно-строительных систем). При этом системная сущность управления должна обнаруживаться проявлением ряда известных свойств. Ниже они приводятся в перечислении С. А. Уварова - автора заимствованного нами научного издания по логистике [7].

1. Автономность - это способность системы функционировать и развиваться в определенных, достаточно широких, пределах независимо от окружающей среды.

2. Целостность - это внутренняя взаимосвязь частей системы с единой целенаправленной деятельностью. «Целостность (связанность) и обособленность (суммативность), - считает С. А. Уваров, - являются не двумя разными свойствами, а крайними случаями одного и того же свойства", но, к сожалению, не определяет его. Напротив, в сочетании с целостностью называет эмерджетность.

3. Эмерджентность - это свойство системы, которое не присуще составляющим ее элементам, рассматриваемым отдельно, вне системы. Иными словами, эмерджентность - это эффект организации, который является результатом возникновения между элементами синергических связей. Синергическая связь при совместных действиях независимых элементов системы обеспечивает увеличение их общего эффекта до величины большей, чем сумма эффектов этих же элементов, действующих независимо.

На следственную зависимость эмерджентности от целостности логистических систем указывает Н. В. Афанасьева [8]. И действительно, есть основания согласиться с тем, что эмерджентность является одной из форм проявления диалектического принципа перехода количественных изменений в качественные. При создании (синтезе) системы как органичного целого за счет вовлечения новых элементов и/или вследствие преобразования структуры взаимосвязей между элементами ее части претерпевают качественные изменения, так что некоторый объект как элемент целостной системы не тождествен аналогичному объекту, взятому изолированно. Всякий эффект взаимосвязи и взаимодействия, не аддитивный по отношению к локальным эффектам, можно рассматривать как проявление эмерджентности.

Системные свойства и приводящие к их возникновению системообразующие процессы описываются в форме законов и закономерностей. Знание этих законов становится важным потому и именно потому, что путем реализации законов можно запустить системообразующие процессы и задать системные свойства. Логистические системы строятся вследствие развития управляемых процессов, основными среди которых следует рассматривать процессы, сопряженные с формированием и обеспечением функционирования логистических цепей взаимодействия элементов системы. При этом свойство эмерджентности, означающее, что система есть нечто большее, чем соединение ее частей, лежит в основе логистического принципа оптимизации и учитывается также при оценке рисков, возникающих в цепи взаимодействия [9].

Связи в цепях взаимодействия участников ипотечно-строительных проектов являются, на наш взгляд, синергическими в силу того, что каждый отдельный участник из состава носителей спроса или носителей предложения, не смог бы осуществить свою цель в отсутствие партнеров. Роли предопределены изначально

\section{Baikal Research Journal}

электронный научный журнал Байкальского государственного университета 
характером специализации участников. Последний обусловливает содержание и формы взаимодействия и этим порождает системообразующие процессы. Синергия при системной организации проектного логистического менеджмента достигается путем интеграции финансовой логистики и материальной логистики - интеграции, которая опосредуется инвестиционным менеджментом.

По общим правилам, управляемые системообразующие процессы в логистике описываются законами организации, включая [10]: закон синергии, закон пропорциональности, закон онтогенеза, закон самосохранения, закон единства анализа и синтеза, закон информированности-упорядоченности, закон композиции.

Законы синергии, пропорциональности, композиции считаются законами преимущественно статической организации (законами строения, морфологии), а законы онтогенеза, самосохранения, единства анализа и синтеза - законами преимущественно динамической организации (законами поведения, функционирования), закон информированности-упорядоченности относится в равной мере и к тем, и к другим. Для системной организации логистического менеджмента важны обе группы законов; процесс системообразования, возникновения статической организации (организации как структуры) есть процесс развертывания динамической организации (организации как функции управления). В этом смысле статика есть продукт динамики или статическая организация одной системы есть следствие динамической организации другой, например, надсистемы.

Законами организации детерминируются свойства систем, в этом смысле следует учитывать, что все они тесно связаны между собой. Это означает, что нельзя принимать во внимание требования одного из них и при этом игнорировать требования другого. Нельзя, например, провести интеграцию, учитывая требование закона онтогенеза, и не использовать объективного отношения, выражаемого законом композиции. Возможно даже, что существует некий организационный метазакон, увязывающий в единое отношение все законы организации, - делая такое предположение, представляется необходимым обратиться к понятию организации. Исследование его должно позволить, по нашим оценкам, раскрыть ряд дополнительных (относительно перечня С. А. Уварова) свойств, характерных для логистических систем.

Согласно общей теории систем организация - это свойство систем обнаруживать взаимозависимое поведение частей системы в рамках целого [11]. Частями системы рассматриваются ее подсистемы, элементы, переменные и т. д. Организация системы проявляется прежде всего в ограничении разнообразия поведения частей системы в рамках целого. В зависимости от целей создания системы и используемых для этого средств возникают различные организации. Свое участие в этом обнаруживает так называемый наблюдатель [11].

Термин «наблюдатель» широко применяется в общей теории систем и кибернетике, аналогичными ему являются термины «исследователь», «экспериментатор», «немашинная часть системы», «субъект управления» и др. Характер участия наблюдателя определяется по его функции в отношении системы. Основное содержание этой функции состоит в формировании наблюдателем системы в соответствии с его целями (исследовательскими, управленческими, организационными и т. д.), т. е. вопреки терминологическому звучанию наблюдатель предстает активным, деятельным элементом, формирующим систему.

По отношению к системе наблюдатель может занимать различные позиции действовать в качестве внешнего наблюдателя, рассматривающего систему извне, и в качестве части исследуемой системы, имеющей возможность влиять на ее состояния. В первом случае поведение системы может быть описано в терминах цели (аксиологически) или в терминах непосредственного влияния одних пере-

\section{Baikal Research Journal}

электронный научный журнал Байкальского государственного университета 
менных на другие (каузально), без употребления понятий целей и средств. Во втором случае цели системы определяются целями наблюдателя или хотя бы корреспондируют с ними, при этом сама система описывается в терминах цели и является самоорганизующейся.

При изучении поведения системы бихевиористическим методом наблюдатель не интересуется ее внутренней организацией и анализирует лишь взаимные изменения некоторых ее переменных, обычно называемых входами и выходами. В этом случае с организацией системы отождествляют преобразование значений входов в значения выходов, соответствующее системе. Такой взгляд на организацию системы является наиболее грубым, но иногда он может оказаться вполне достаточным. Однако в ряде случаев необходимо рассматривать и внутреннюю организацию - структуру системы путем разбиения ее на части (подсистемы или элементы) и фиксирования связей между ними. В этом состоит процесс структуризации системы.

Структура является непременным атрибутом всякой организационной системы. Определяя организацию, наблюдатель прежде всего определяет структуру системы, используя ее формальное отображение в виде плоского неориентированного графа, вершины которого соответствуют элементам системы, а дуги - связям между ними. Однако, анализируя закономерности поведения отдельных частей системы, наблюдатель опять-таки использует бихевиористический метод, что не исключает возможности дальнейшей структуризации отдельных частей системы. На этом строится иерархия - один из традиционных типов структуры в системах управления.

Организационные системы часто имеют детерминированную и неизменную во времени структуру. В других случаях структура системы может меняться стохастически - при этом для описания организации используют статистические характеристики структуры системы. Для систем, обнаруживающих адаптивное поведение, характерна способность к целенаправленному изменению собственной структуры в меняющейся среде. Поэтому при изучении адаптивных систем в первую очередь анализируются закономерности динамики их структурных изменений - такой анализ обычно является весьма сложным, однако он необходим для прогноза поведения адаптивной системы или управления ею.

Организация и структура системы тесно связаны с ее динамическими характеристиками и устойчивостью. Способ соединения частей системы в значительной мере определяет ее чувствительность к изменению параметров под воздействием внешней среды. Структуры формируемых систем обычно строятся таким образом, чтобы изменение параметров системы (в определенных границах) не приводило к потере необходимых динамических качеств и устойчивости. Если жесткая структура системы не обеспечивает этого, используется принцип адаптации, действие которого в наиболее развитых формах приводит к изменяющейся гибкой структуре.

При изучении большой системы обычно происходит постоянное смещение границы между нею и внешней средой, что делает необходимым пересмотр структуры системы. При анализе больших систем наблюдатель исследует организацию и структуру системы в нескольких аспектах, поскольку ни один аспект, взятый отдельно, не позволяет получить адекватное представление.

Степень организованности системы должна соответствовать степени организованности окружающей среды в том смысле, что если среда, в которой функционирует система, богата внутренними связями, то система с соответствующей сложностью организации лучше приспосабливается и выживает в такой среде. Необходимая степень организованности системы в заданной среде определяется законом необходимого разнообразия. Этот закон устанавливает, что эффективное

\section{Baikal Research Journal}

электронный научный журнал Байкальского государственного университета 
управление большими системами, в том числе экономическими, к категории которых следует, на наш взгляд, отнести и логистические ипотечно-строительные системы, не осуществимо с помощью «простых» средств [11].

В соответствии с законом необходимого разнообразия для управления большой системой управляющая система должна иметь значительное собственное разнообразие. Разнообразие может быть достигнуто структуризацией управляющей системы, что применительно к логистической ипотечно-строительной системе означает формирование взаимодействующих подсистем управления, каждая из которых решает некоторую частную задачу в условиях относительной самостоятельности в рамках установленной иерархии. При этом в управляющей системе предполагается наличие Координационного центра - центрального органа управления, функцией которого является логистическая координация действий подсистем, обеспечивающая согласование собственных интересов подсистем с целью (интересами) всей системы. Разнообразие всей управляющей системы при полной независимости подсистем измеряется произведением количества разнообразия каждой из них; при наличии взаимосвязей подсистем эта величина сокращается по мере того, как усиливается взаимозависимость.

Для больших систем свойственна несводимость их структуры к какой-либо одной иерархии. Наличие различных ракурсов структурной организации объекта управления и индуцируемых этим различных аспектов управления приводит к одновременному формированию и функционированию различных иерархических структур в соответствии с различными принципами членения множества элементов, составляющих объект управления. Взаимодействия между такими структурами (и элементами различных структур) не ограничиваются простыми отношениями соподчинения в иерархии.

На основании изложенного следует заключить, что в реализации закона необходимого разнообразия большое значение приобретает выбор способа объединения элементов множества $M^{\circ}$ в подмножества $M_{i}^{k}$. Такое объединение производится либо экспертными методами, либо с использованием количественной оценки сходства элементов $M^{\circ}$ : в одно подмножество объединяются сходные элементы. Содержание понятия «сходство» зависит от природы элементов $M^{\circ}$. Например, если элементы $M^{\circ}$ - это участники одного ипотечно-строительного проекта, то в качестве признаков сходства могут быть использованы характеристики потоковых процессов и продуцируемых ими потоков как признаки связности в цепях взаимодействия; если же - это хозяйствующие субъекты, принимающие участие в реализации нескольких проектов, то признаками их сходства могут быть: характер специализации (строительная компания, финансовый институт и т. д.), объемы выполняемых работ, географическое расположение, общность бизнес-технологий и др. В ряде случаев оценки сходства удается получить на основе теоретических исследований; однако более распространенный способ - это использование методов классификации, примыкающих к алгоритмам распознавания образов.

Управление в системе с иерархической структурой, где каждая из подсистем решает некоторую частную задачу в условиях относительной самостоятельности, предполагает, что управленческие решения логистического содержания, разработанные всеми подсистемами некоторого уровня $k$, подчиненными подсистеме более высокого уровня $k-1$, координируются этой последней. При итеративном характере процесса выработки управляющего воздействия могут производиться многократно: корректировка решений подсистем нижележащего уровня, их последующая координация «наверху», новая корректировка и т. д.

Перспектива создания логистической ипотечно-строительной системы в статусе большой системы требует того, чтобы не ограничиваться рассмотрением лишь

\section{Baikal Research Journal}

электронный научный журнал Байкальского государственного университета 
информационных взаимосвязей между управляющей и управляемой системами. Это обосновывается тем, что управление большой системой отвлекает значительное количество трудовых, материальных и финансовых ресурсов, что ставит специфическую задачу сопоставления дополнительных затрат на совершенствование системы управления и обусловленного этими затратами эффекта.

Сложность управления большими системами предопределяет необходимость применения в управляющих системах формализованных процедур принятия решений, что, в свою очередь, требует того, чтобы воспользоваться принципом внешнего дополнения - он реализует механизм компенсации последствий, обусловливаемых неполнотой формализованных схем управления. Схема управления в общем виде включает прогноз состояний среды и нормативное определение управляющих воздействий. Однако при большой сложности объекта управления и прогноз, и нормативное моделирование формальными методами могут быть осуществлены лишь приближенно. Поэтому становится необходимым содержательный контроль формализованной схемы управления, следствием которого будут неформально принимаемые решения о корректировке формально вырабатываемых управляющих воздействий и прогнозов состояния среды. Внешним дополнением обычно называют всю совокупность неформальных процедур корректировки формализованно полученного управленческого решения, а также введения экзогенных параметров в модель управления. В широком, смысле под принципом внешнего дополнения понимают необходимость применения при управлении большой системой подобных неформальных процедур [11].

В содержании научно-практических рекомендаций по системной организации проектного логистического менеджмента требуется, на наш взгляд, учесть следующее:

1. Целенаправленное применение законов организации в логистических ипотечно-строительных системах позволяет рассматривать их в качестве самоорганизующихся. Таковыми они являются вследствие того, что элементы этих систем принимают решения и этим инициируют и обеспечивают течение управляемых системообразующих процессов.

2. Между элементами-участниками системы возникают коалиции, дающие им определенные преимущества, т. е. формируется структура, организация системы. Логистическая ипотечно-строительная система отличается от иерархической. По нашим оценкам, это - не столько иерархическая, сколько коалиционная структура, которая строится в большей степени на неформальной, чем на формальной основе, и относится к категории матричных структур. Последние разработаны в большей степени применительно к микроуровню, т. е. уровню предприятия, но могут быть адаптированы и к уровню среднего звена - коалиционной структуре, в пользу чего свидетельствует главный принцип структуризации - распределение функций «между центром и подразделениями» [12].

3. Понятием логистической ипотечно-строительной системы нами обобщаются две разновидности систем: система управления пулом ипотечно-строительных проектов и система управления одним, конкретным ипотечно-строительным проектом.

Система управления пулом - это постоянно-действующая система, которая формируется на базе коалиции банков, АИЖК, работающих с пулом, - коалиции, которая может быть расширена в своих масштабах за счет привлечения к участию страховых компаний, девелоперских фирм и др. путем выстраивания цепей взаимодействия на долгосрочной основе в соответствии с применяемыми ипотечными схемами. В виду заложенной в ней коалиционности эта система должна быть признана системой мезоуровня [13].

\section{Baikal Research Journal}

электронный научный журнал Байкальского государственного университета 
Описанные научно-практические рекомендации по системной организации проектного логистического менеджмента относятся именно к этой разновидности логистических ипотечно-строительных систем, которую, следует отметить, корректнее было бы назвать ее составляющей [14-16].

Наше мнение основывается на том, что наряду с этой мезосистемой на уровне каждого из участников, работающего с одним, конкретным ипотечно-строительным проектом, должна действовать своя собственная логистическая система логистическая система ипотечно-строительного проекта.

4. Суть наших рекомендаций сводится к тому, что логистические системы ипотечно-строительного проекта должны быть созданы на уровне каждого из участников, включая коммерческие банки, ипотечное агентство АИЖК и их региональных операторов на местах. При этом их функционирование должно координироваться мезологической системой, которая в данном случае принимает на себя роль Координационного центра в лице одного из участников коалиции или специально созданного коалиционного управленческого органа.

Как уже отмечалось, логистическая система ипотечно-строительного проекта, как и логистические системы участников ипотечно-строительного проекта должны иметь дивизиональную структуру с той лишь разницей, что первую будет целесообразным сориентировать на конкретные сегменты рынка ипотечного кредитования и/или жилищного строительства, а вторые - на тип клиентов.

5. В свете реализации национального проекта «Доступное и комфортное жилье - гражданам России», а также Федеральной программы «Жилище», Федеральной программы ипотечного кредитования ориентацию на первичный рынок жилья следует, очевидно, признать приоритетной, тем более что, так или иначе этот ориентир определяет и типологию клиентов ипотеки. Более того, первичный рынок следует сегментировать по типам жилья:

- односемейные (индивидуальные) объекты жилой недвижимости;

- многосемейные объекты жилой недвижимости;

- апартаменты, как объект нежилой недвижимости.

По данным АИЖК предполагается привлечь через инструмент коллективных инвестиций общий объем инвестиций не менее 100 млрд р. к 2020 г. Реализация этой цели, на наш взгляд, во многом будет зависеть от своевременности и эффективности перестройки систем управления в ипотечно-строительной сфере на основе проектно-ориентированного подхода.

\section{Список использованной литературы}

1. Апенько С. Н. Предпосылки создания региональной системы мониторинга управления проектами на предприятиях / С. Н. Апенько // Известия Иркутской государственной экономической академии. - 2016. - T. 26, № 4. - C. 573-582. - DOI: $10.17150 / 2500$ 2759.2016(4).573-582.

2. Харрингтон Дж. Совершенство управления проектами: искусство совершенствования управления проектами : пер. с англ. / Дж. Харрингтон, Т. Макнеллис. - М. : Стандарты и качество, 2007. - $232 \mathrm{c.}$

3. Логистика и управление цепями поставок: учебник для академического бакалавриата / под ред. В. В. Щербакова. - М. : Юрайт, 2015. - 582 с.

4. Щербаков В. В. Логистика в управлении ипотечно-строительными проектами: состояние и перспективы трансформации / В. В. Щербаков, Т. И. Кубасова // Проблемы современной экономики. - 2009. - № 3. - С. 237-239.

5. Кубасова Т. И. Применение проектно- ориентированного подхода в логистике / Т. И. Кубасова // Трансформации логистических систем в современных условиях : материалы Междунар. науч.-практ. конф. - Иркутск : Изд-во БГУЭП, 2015. - С. 65-70.

6. Кубасова Т. И. Управление логистикой ипотечно-строительных проектов : дис. ... д-ра экон. наук : 08.00.05 / Т. И. Кубасова. - СПб., 2009. - 368 с.

\section{Baikal Research Journal}

электронный научный журнал Байкальского государственного университета 
7. Уваров С. А. Логистика: общая концепция, теория, практика : монография / С. А. Уваров. - СПб. : Инвест-НП, 1996. - 232 с.

8. Афанасьева Н. В. Логистические системы и российские реформы / Н. В. Афанасьева. - СПб. : : С.-Петерб. ун-т экономики и финансов, 1995. - 147 с.

9. Плетнева Н. Г. Аналитические методы управления логистическими системами / Н. Г. Плетнева. - СПб. : С.-Петерб. гос. инженер.-экон. ун-т, 2007. - 211 с.

10. Радченко Я. В. Законы организации и их роль в перестройке структур управления экономикой / Я. В. Радченко // Известия Академии наук СССР. Сер. Экономическая. 1988. - № 5. - C. 3-21.

11. Математика и кибернетика в экономике : словарь-справочник / И. Гонтарева, М. Немчинова, А. Попова ; отв. ред. Н. П. Федоренко. - Изд. 2-е, перераб. и доп. - М. : Экономика, 1975. - 700 с.

12. Виссема X. Менеджмент в подразделениях фирмы: предпринимательство и координация в децентрализованной компании : пер. с англ. / Х. Виссема. - М. : Инфра-М, 1996. - 287 с.

13. Сковронек Ч. Логистика на предприятии : учеб.-метод. пособие / Ч. Сковронек, 3. Сариуш-Вольский. - М. : Финансы и статистика, 2004. - 297 с.

14. Мясникова Л. А. Мезологистика: информация и ожидания / Л. А. Мясникова. СПб. : Изд-во С.-Петерб. ун-та экономики и финансов, 1998. - 178 с.

15. Зуева О. Н. Логистика взаимодействия потоковых процессов домашних хозяйств и организаций торговли : автореф. дис. ... д-ра экон. наук : 08.00.06 / О. Н. Зуева. — Екатеринбург, 2007. - 45 с.

16. Кубасова Т. И. Управление логистикой ипотечно-строительных проектов : автореф. дис. ... д-ра экон. наук : 08.00.05 / Т. И. Кубасова. - СПб., 2009. — 36 с.

\section{References}

1. Apenko S. N. Prerequisites for creating and developing a regional monitoring system of project management in enterprises. Izvestiya Irkutskoi gosudarstvennoi ekonomicheskoi akademii = Bulletin of Irkutsk State Economics Academy, 2016, vol. 26, no. 4, pp. 573-582. DOI: 10.17150/2500-2759.2016.26(4).573-582. (In Russian).

2. Harrington H. J., McNellis T. Project Management Excellence: The Art of Excelling in Project Management. Chico, Paton Press LLC, 2006. 174 p. (Russ. ed.: Harrington H. J., McNellis T. Sovershenstvo upravleniya proektami: iskusstvo sovershenstvovaniya upravleniya proektami. Moscow, Standarty i kachestvo Publ., 2007. 232 p.).

3. Shcherbakov V. V. (ed.). Logistika i upravlenie tsepyami postavok [Logistics and Supply Chain Management]. Moscow, Yurait Publ., 2015. 582 p.

4. Shcherbakov V. V., Kubasova T. I. Logistics in mortgage and construction project management: state and prospects of transformation. Problemy sovremennoi ekonomiki $=$ Problems of Modern Economy, 2009, no. 3, pp. 237-239. (In Russian).

5. Kubasova T. I. Using the project-oriented approach in logistics. Transformatsii logisticheskikh sistem $v$ sovremennykh usloviyakh. Materialy Mezhdunarodno-prakticheskoi konferentsii [Transformation of logistic systems in current context terms. Materials of International Research Conference]. Irkutsk, Baikal State University of Economics and Law Publ., 2015, pp. 65-70. (In Russian).

6. Kubasova T. I. Upravlenie logistikoi ipotechnostroitelnykh proektov. Dokt. Diss. [Logistics Management for Mortgage and Construction Projects. Doct. Diss.]. Saint Petesburg, 2009. $368 \mathrm{p}$.

7. Uvarov S. A. Logistika: obshchaya kontseptsiya, teoriya, praktika [Logistics: general concept, theory, practice]. Saint Petersburg, Invest-NP Publ., 1996. 232 p.

8. Afanaseyeva N. V. Logisticheskie sistemy i rossiiskie reformy [Logistic systems and Russian reforms]. Saint Petersburg State University of Economics and Finances Publ., 1995. 147 p.

9. Pletneva N. G. Analiticheskie metody upravleniya logisticheskimi sistemami [Analytical methods of logistic system management]. Saint-Petersburg State University of Economics Publ., 2007. 211 p.

10. Radchenko Ya. V. Laws of the organization and their role in rearranging the structures of economic management. Izvestiya Akademii nauk SSSR. Ser. Ekonomicheskaya = Herald of the USSR Academy of Sciences, Series. Economic, 1988, no. 5, pp. 3-21. (In Russian).

\section{Baikal Research Journal}


11. Gontareva I., Nemchinova M., Popova A., Fedorenko N. P. (eds). Matematika i kibernetika $v$ ekonomike. Slovar'-spravochnik [Mathematics and cybernetics in economy. Glossary]. $2^{\text {nd }}$ ed. Moscow, Ekonomika Publ., 1975. 700 p.

12. Vissema H. Menedzhment $v$ podrazdeleniyakh firmy: predprinimatel'stvo i koordinat siya $v$ detsentralizovannoi kompanii [Unit Management: Entrepreneurship and Coordination in the Decentralized Firm]. Moscow, Infra-M Publ., 1996. 287 p.).

13. Skovronek Ch., Sariush-Vol'sky Z. Logistika na predpriyatii [Logistics in the company]. Moscow, Finansy i statistika Publ., 2004. 297 p.

14. Myasnikova L. A. Mezologistika: informatsiya i ozhidaniya [Mezologistics: information and expectations]. Saint Petersburg State University of Economics and finances Publ., 1998. $178 \mathrm{p}$.

15. Zuyeva O. N. Logistika vzaimodeistviya potokovykh protsessov domashnikh khozyaistv $i$ organizatsii torgovli. Avtoref. Dokt. Diss. [Logistics of interacting of stream processes in households and settlement of trade. Doct. Diss. Thesis]. Yekaterinburg, 2007. 45 p.

16. Kubasova T. I. Upravlenie logistikoi ipotechno-stroitelnykh proektov. Avtoref. Dokt. Diss. [Logistics Management for Mortgage and Construction Projects. Doct. Diss. Thesis]. Saint Petersburg, 2009. 36 p.

\section{Информация об авторе}

Кубасова Татьяна Иннокентьевна - доктор экономических наук, профессор, кафедра логистики и коммерции, Байкальский государственный университет, 664003, г. Иркутск, ул. Ленина, 11, e-mail: Lenina424@yandex.ru.

\section{Author}

Tatyana I. Kubasova - Doctor habil. (Economics), Professor, Chair of Logistics and Commerce, Baikal State University, 11 Lenin St., 664003, Irkutsk, Russian Federation; e-mail: Lenina424@yandex.ru.

\section{Библиографическое описание статьи}

Кубасова Т. И. Организационное проектирование логистических ипотечно-строительных систем коалиционного типа / Т. И. Кубасова // Baikal Research Journal. — 2016. T. 7, № 6. - DOI: 10.17150/2411-6262.2016.7(6).10.

\section{Reference to article}

Kubasova T. I. Organizational designing of logistic mortgage and construction systems of coalition type. Baikal Research Journal, 2016, vol. 7, no. 6. DOI: 10.17150/24116262.2016.7(6).10. (In Russian).

\section{Baikal Research Journal}

